\title{
Forging, textures, and deformation systems in a B2 FeAl alloy
}

\author{
P. Zhao, D. G. Morris, and M. A. Morris-Mun̄oz \\ Institute of Structural Metallurgy, University of Neuchâtel, Avenue de Bellevaux 51, \\ 2000 Neuchâtel, Switzerland; and CENIM, Avenida Gregorio del Amo 8, \\ 28040 Madrid, Spain
}

(Received 23 October 1997; accepted 20 August 1998)

High-temperature forging experiments have been carried out by axial compression testing on a $\mathrm{Fe}-41 \mathrm{Al}-2 \mathrm{Cr}$ alloy in order to determine the deformation systems operating under such high-speed, high-temperature conditions, and to examine the textures produced by such deformation and during subsequent annealing to recrystallize. Deformation is deduced to take place by the operation of $\langle 111\rangle\{110\}$ and $\langle 111\rangle\{112\}$ slip systems at low temperatures and by $\langle 100\rangle\{001\}$ and $\langle 100\rangle\{011\}$ slip systems at high temperatures, with the formation of the expected strong $\langle 111\rangle$ textures. The examination of the weak $\langle 100\rangle$ texture component is critical to distinguishing the operating slip system. Both texture and dislocation analyses are consistent with the operation of these deformation systems. Recrystallization takes place extremely quickly at high temperatures (above $800{ }^{\circ} \mathrm{C}$ ), that is within seconds after deformation and also dynamically during deformation itself. Recrystallization changes the texture such that $\langle 100\rangle$ textures superimpose on the deformation texture. The flow stress peak observed during forging is found at a very high temperature. Possible origins of the peak are examined in terms of the operating slip systems.

\section{INTRODUCTION}

The deformation of iron aluminide alloys at high temperatures is characterized by a peak in flow stress at intermediate temperatures. ${ }^{1-4}$ While early studies on FeAl alloys did not show such a peak, ${ }^{5}$ subsequent studies make it clear that the peak exists for all alloy compositions, extending from $\mathrm{Fe}_{3} \mathrm{Al}$ stoichiometry up to near FeAl stoichiometry, and that it is important to avoid the confusing strengthening effects of vacancy hardening in analyses. ${ }^{6,7}$ A considerable amount of work has examined the nature of the peak in both families of alloys and suggested reasons for its origin..$^{8-10}$

For FeAl based alloys it seemed for some time reasonably clear that deformation by glide of $\langle 111\rangle$ superdislocations at low temperatures was superseded by deformation by glide of $\langle 100\rangle$ dislocations at temperatures above the peak. ${ }^{4-6}$ The reasons for the change of Burgers vector seem to be tied to the locking of $\langle 111\rangle$ superdislocations by mechanisms such as dislocation decomposition (to $\langle 110\rangle$ and $\langle 100\rangle$ dislocations), ${ }^{11}$ climb locking, ${ }^{9,12}$ or vacancy hardening. ${ }^{7}$ It may also be noted that some of the hardening models, for example vacancy hardening, do not require, a priori, any change of Burgers vector, and the stress peak could be produced by the existence of a temperature range where $\langle 111\rangle$ dislocations are pinned followed by a range where they are released. ${ }^{7}$ Some questions have been raised about the validity of these results by recent experiments ${ }^{9,13}$ ex- amining changes in dislocation structures as a material is strained ${ }^{9}$ and during cooling after high temperature straining. ${ }^{13}$ Yoshimi et al. ${ }^{9}$ showed that there was a change of operating dislocation Burgers vector over the first $1-2 \%$ strain on deforming $\mathrm{Fe} 39.5 \mathrm{Al}$ near its flow stress peak, with $\langle 111\rangle$ superdislocations present initially at the low strain levels where flow stresses are generally measured and $\langle 100\rangle$ dislocations at strains of $1-2 \%$, where previous dislocation and slip step analyses had been carried out. ${ }^{4,5,9}$ Studies of Fe37Al deformed at high strain rate $\left(\approx 2 \times 10^{-2} / \mathrm{s}\right)$ and subsequently rapidly cooled to avoid possible changes of dislocation structures after deformation ${ }^{13}$ confirmed that $\langle 111\rangle$ superdislocations controlled deformation under these conditions. While raising doubts about the dislocation mechanisms controlling flow stress at high temperatures, the present situation is not completely clear and consistent, with for example reports of significant amounts of glide of $\langle 100\rangle$ dislocations at $1 \%$ strain already, ${ }^{5}$ the appearance of pronounced yield stress drops on straining from yield to about $1-2 \%$ as $\langle 100\rangle$ dislocations dominate deformation, ${ }^{4,9}$ and the observation of $\langle 111\rangle$ dislocations at $4-5 \%$ strain after higher temperature $\left(650{ }^{\circ} \mathrm{C}\right)$ straining. ${ }^{13}$

For $\mathrm{Fe}_{3} \mathrm{Al}$ based alloys the situation is equally confused. Some studies report the stress peak to be due to pinning of $\langle 111\rangle$ superdislocations, for example by relaxation of the anti-phase boundary of the dislocation, by changes in the dislocation core structure or by cross 
slip, without any change to $\langle 100\rangle$ dislocations,,${ }^{1,2,14-16}$ whereas other reports consider the $\langle 111\rangle$ to $\langle 100\rangle$ change to be important. ${ }^{3,12}$ Recent studies on texture evolution during high temperature processing of such $\mathrm{Fe}_{3} \mathrm{Al}$ alloys have shown that the dominant operating deformation systems can be deduced from the textures produced. ${ }^{17-19}$ For alloys containing about $28 \% \mathrm{Al}$ and $0-5 \% \mathrm{Cr}$ deformed by rolling, forging, or extrusion at temperatures from about 550 to $900{ }^{\circ} \mathrm{C}$, where the alloys have B2 order, it has been clearly shown that the textures produced can be explained by the operation of $\langle 111\rangle\{110\}$ and $\langle 111\rangle\{112\}$ slip systems. Such temperatures are considerably higher than the stress peak for these materials, and therefore clearly raise doubts about the relevance of the post mortem TEM results which showed $\langle 100\rangle$ dislocations after high temperature deformation. ${ }^{13}$ The explanation for the origin of the observed $\langle 100\rangle$ dislocations could again be the decomposition of $\langle 111\rangle$ superdislocations, produced during deformation, ${ }^{11,13,20}$ during the coolingdown period after deformation. Observed dislocation structures then have no relevance to the initial deformation stage.

In view of the doubts about the validity of post mortem TEM observations to the prior deformation mechanisms, the present study has examined both dislocation structures and textures produced by the high temperature deformation of a B2 ordered FeAl alloy. Deformation has been carried out by high temperature axial compression forging to large strains, assuring a significant texture change, with the forging terminated by a very rapid quench, limiting the extent of any postdeformation modification of dislocation structures. The texture simulations carried out by Kad et al. ${ }^{19}$ predict the texture changes expected under such forging conditions when different deformation systems operate, and can be used to interpret the observed textures. There has been only limited attention given to the textures formed on deforming $\mathrm{B} 2 \mathrm{FeAl},{ }^{21}$ showing a strong $\langle 111\rangle$ wire texture after extrusion, but with the texture depending on the precise starting state and alloy composition. The present study attempts a more complete correlation of deformation textures and slip systems in $\mathrm{B} 2$ ordered $\mathrm{FeAl}$ on straining over a wide range of high temperatures.

\section{EXPERIMENTAL TECHNIQUES}

The alloy used for the present study had the composition $\mathrm{Fe}-41 \mathrm{Al}-2 \mathrm{Cr}$ (at.\%) and was supplied as a cast and forged pancake about $20 \mathrm{~mm}$ thick and $10 \mathrm{~cm}$ in diameter. Cylindrical samples of diameter $7.5 \mathrm{~mm}$ and height $15 \mathrm{~mm}$ were cut out from this pancake for the compression forging experiments. The sample ends were mechanically polished flat and perpendicular to the cylinder axis. Samples were annealed for $1 \mathrm{~h}$ at $1000{ }^{\circ} \mathrm{C}$, followed by $1 \mathrm{~h}$ at $700{ }^{\circ} \mathrm{C}, 1 \mathrm{~h}$ at $600{ }^{\circ} \mathrm{C}$, and $24 \mathrm{~h}$ at $500{ }^{\circ} \mathrm{C}$ in order to ensure a stabilized, recrystallized structure with no retained excess vacancies.

Forging consisted of an axial compression at a nominal strain rate of $1 / \mathrm{s}$, and immediately after forging the sample was thrown into a nearby brine bath. The time between deformation and quenching was estimated to be about $1 \mathrm{~s}$. Forging strain was controlled as a height reduction of about $45 \%$ for samples at high temperatures, but of only $25 \%$ at temperatures of $600{ }^{\circ} \mathrm{C}$ and below because of cracking occurring during forging. Samples were preheated for about $20 \mathrm{~min}$ under protective atmosphere, with the tungsten carbide forging plattens preheated to the same temperature to ensure minimal temperature changes before or during forging. Ends were lubricated with a molybdenum sulfide-based grease, with fine concentric grooves on the platten surfaces to retain a supply of the grease. Load and elongation data from a quartz gauge and a displacement transducer attached near the forging plattens were recorded during forging using a Power Macintosh and LabView software data acquisition system. The data were converted to true stress-true strain plots, assuming constant sample volume and uniform cylindrical shape. A few examples are illustrated in Fig. 1. Data were collected initially (over the elastic range and near plastic yielding) at total strain increments of below $0.1 \%$, and later at strain increments of the order of $0.5 \%$.

Forging experiments were carried out at temperatures ranging from 400 to $1000{ }^{\circ} \mathrm{C}$ with the sample generally quenched immediately after deformation. A few additional samples were held for about $5 \mathrm{~s}$ at their forging temperatures at the end of deformation, before quenching, to assess the kinetics of structural changes after deformation. In addition, some of the forged samples were given an anneal of $10 \mathrm{~min}$ at $800{ }^{\circ} \mathrm{C}$ to examine the changes brought about by this treatment.

Samples were sectioned parallel to the cylinder axis and the central region was examined by optical, scanning electron and transmission electron microscopy, as well as by x-ray diffraction. Optical examinations were carried out on polished sections etched using a mixture of $12 \mathrm{ml}$ $\mathrm{HCl}, 6 \mathrm{ml} \mathrm{HNO}, 7 \mathrm{ml} \mathrm{HF}$, and $80 \mathrm{ml}$ water. SEM was carried out using a Cambridge Stereoscan 360 in the backscattered electron mode on sections electropolished using a $33 \% \mathrm{HNO}_{3}$ and $67 \%$ methanol mixture at $5{ }^{\circ} \mathrm{C}$ and $15 \mathrm{~V}$. TEM was carried out using a Philips CM200 instrument on thin foils prepared by twin jet polishing using the same $\mathrm{HNO}_{3}$-methanol mixture as above at $-10{ }^{\circ} \mathrm{C}$ and $9 \mathrm{~V}$. Dislocation Burgers vector, line direction, and habit (glide) planes were determined according to standard rules for invisibility using several imaging $\mathbf{g}$ vectors, and standard stereographic analysis methods. The double tilt Compustage sample holder allowed tilting over $\pm 45^{\circ}$ and $\pm 60^{\circ}$ about two orthogonal axes and it was possible to examine several major zone 


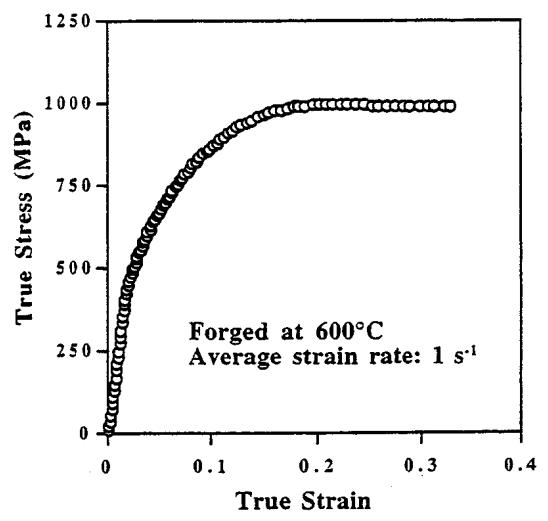

(a)

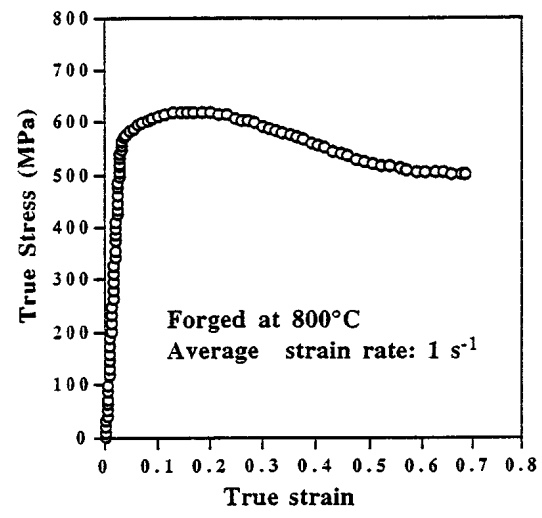

(b)

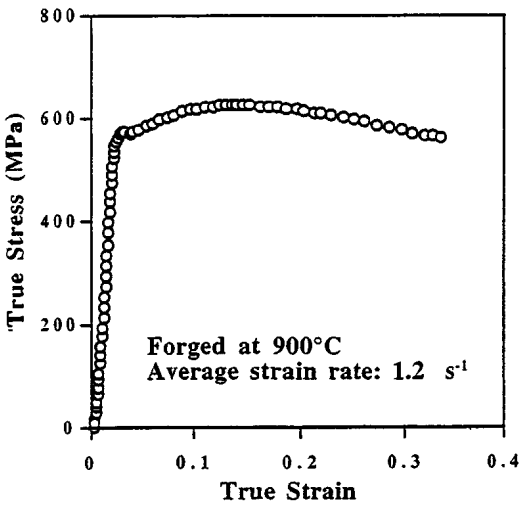

(c)

FIG. 1. True stress-true strain plots showing the evolution of flow stress during compression by forging (strain rate about $1 / \mathrm{s}$ ). The examples shown were obtained during forging at (a) $600{ }^{\circ} \mathrm{C}$, (b) $800{ }^{\circ} \mathrm{C}$, and (c) $900{ }^{\circ} \mathrm{C}$. These samples were strained to total height reductions of about 25,45 , and $45 \%$, respectively.

axes for a given area, ensuring that several independent imaging $\mathbf{g}$ vectors were used and stereographic analysis was possible over a wide angular range.

X-ray diffraction was carried out on polished sections through the forged cylinders, transverse to the cylinder axis. Studies were carried out using a Philips MPD 1800 diffractometer operating in the standard $\theta / 2 \theta$ scanning mode using monochromated $\mathrm{Cu} \mathrm{K}_{\alpha}$ radiation. Scanning was carried out over a sufficiently wide angular range that the 110, 200, and 211 fundamental reflections, as well as the 111 superlattice reflection, were measured. (The fundamental 222 reflection occurs at too high a Bragg angle for the instrument used and could not be measured.) Textures were estimated according to the relative intensities of these peaks, as described elsewhere. ${ }^{22}$ This method thus provides quantitative information about the proportion of each type of plane to be found in the few degrees (solid angle determined by the dispersion of the x-ray slits used) around the forged cylinder axis. The observed intensities of the 110-111-200-211 reflections $\left(I_{110}, I_{111}, I_{200}\right.$, and $\left.I_{211}\right)$ were normalized against the intensities $\left(I_{h k l}^{0}\right)$ expected for a texture-free $\mathrm{Fe}-41 \mathrm{Al}-2 \mathrm{Cr}$ sample (similar to the intensities provided by standard powder diffraction data) as $I_{110} / I_{110}^{0}, I_{111} / I_{111}^{0}, I_{200} / I_{200}^{0}$, and $I_{211} / I_{211}^{0}$, and these intensity ratios used to characterize the state of texture. The calculated intensities of the texture-free $\mathrm{Fe}-41 \mathrm{Al}-2 \mathrm{Cr}$ sample were determined supposing (for the 111 superlattice reflection) that the excess $\mathrm{Fe}$ and the $\mathrm{Cr}$ lay on the $\mathrm{Al}$ sites of the B2 lattice. ${ }^{23}$ Thus, for example, the intensity ratios $(110 / 111 / 200 / 211) 1 / 1 / 1 / 1$ indicate the absence of any texture, the $1 / 5 / 3 / 1$ indicates the presence of a strong $\langle 111\rangle$ texture with a weaker $\langle 200\rangle$ texture. The above texture data will be presented here as $0.25 / 0.25 / 0.25 / 0.25$ and $0.1 / 0.5 / 0.3 / 0.1$ to indicate the fraction of each type of plane perpendicular to the cylinder axis.

\section{RESULTS}

\section{A. Mechanical behavior during forging}

Variations of flow stress during compression forging are illustrated in Fig. 1. It should be recalled that these data differ from usual laboratory compression testing by the high strain rate, near $1 / \mathrm{s}$ for the present experiments, and by the high total strain given to ensure a large change in the texture present. For relatively low temperatures, $800{ }^{\circ} \mathrm{C}$ and below, yielding appeared continuous with no yield discontinuity or plateau (at the strain resolution of the data collection system, about $0.05-0.1 \%$ ). Yield was followed by a period of strong work hardening, throughout the entire forging process at 400 and $500{ }^{\circ} \mathrm{C}$, but progressively limited to smaller strains at higher temperatures as stress saturation or even stress fall occurred [at 600 and at $700-1000{ }^{\circ} \mathrm{C}$, respectively; see Figs. 1(a)-1(c)]. Such flow stress saturation and fall is associated with dynamic recovery and recrystallization, which took place so rapidly at $1000{ }^{\circ} \mathrm{C}$ that yielding was almost immediately followed by a stress fall. Forging at $900{ }^{\circ} \mathrm{C}$ was unique here in showing a small stress plateau at the yield point, somewhat similar to that reported by Yoshimi et al. on testing FeAl near the temperature of its flow stress peak. ${ }^{4,9}$

Figure 2 shows the yield stress (flow stress at $0.2 \%$ plastic strain) as a function of test temperature for the present forging experiments and also for compression tests carried out on the same material at a usual laboratory strain rate (unpublished work). The two sets of data differ essentially in the temperature of the flow stress maximum, which is the usual value of about $500{ }^{\circ} \mathrm{C}^{4,9,10}$ for laboratory testing and the very high value of about $800{ }^{\circ} \mathrm{C}$ for the present forging experiments. In the present data it is seen that both the regions of increasing flow stress $\left(300-500\right.$ and $\left.400-800{ }^{\circ} \mathrm{C}\right)$ and the regions of decreasing flow stress (500-600 and 


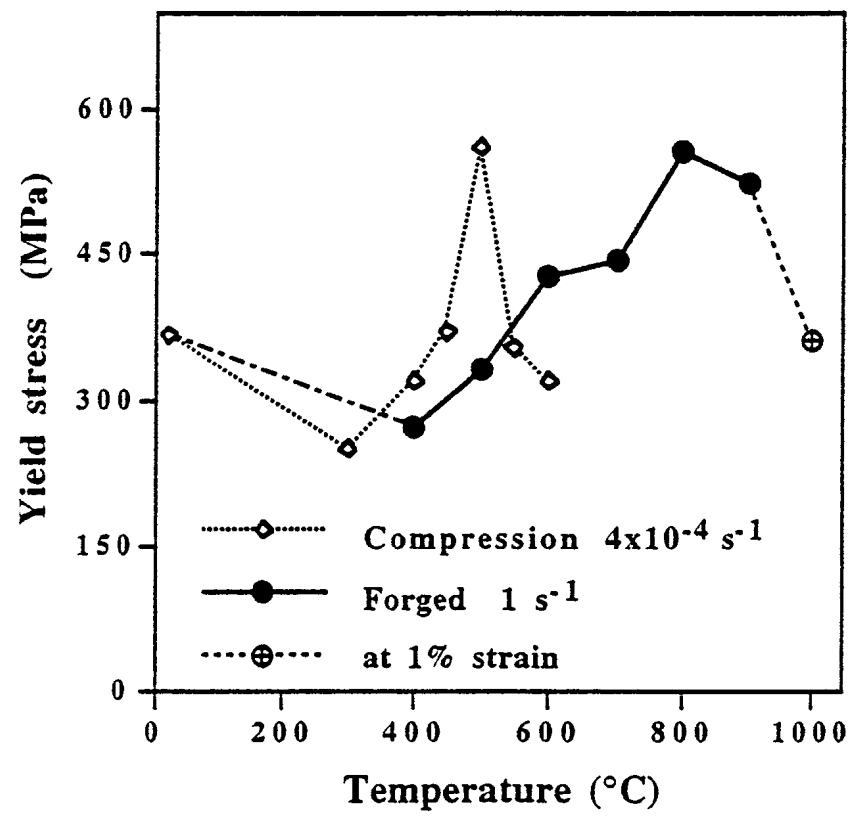

FIG. 2. Yield stress values measured during high strain-rate compression forging and during standard slow laboratory compression testing.

$800-1000{ }^{\circ} \mathrm{C}$ ) are displaced to higher temperatures by the higher rate of straining.

\section{B. Microstructural evolution}

Examinations on the initial material showed the starting microstructure to be single phase, equiaxed polycrystalline with a grain size of the order of $0.5-1 \mathrm{~mm}$. The microstructures after forging have been examined for all the forged samples, but only a few examples of the structural changes will be presented here. The results of microstructural changes taking place during deformation or on subsequent annealing are summarized in Table I.

On forging at temperatures of $700{ }^{\circ} \mathrm{C}$ and below, followed by a rapid quench, there were no clear signs of recrystallization, and the original grains were filled with a high dislocation density, showing some tendency to the formation of a dislocation cell structure, and at the high temperatures in this range some recovery to a dislocation subgrain structure. There was no obvious influence of the speed of quench (immediately after forging, or after a $5 \mathrm{~s}$ wait) on the sample forged at $600{ }^{\circ} \mathrm{C}$, suggesting that recovery and recrystallization was rather slow (requiring more than $5 \mathrm{~s}$ ) at this temperature.

After forging to $45 \%$ height reduction at $800{ }^{\circ} \mathrm{C}$ the central region of the forged sample showed a mixed structure of elongated cells or subgrains and fine, equiaxed grains and subgrains several microns in size; see Fig. 3. The structure varied from place to place, probably depending on the orientation of the initial grain. The
TABLE I. List of forging experiments carried out, and the evolution of fraction recrystallized, grain size in recrystallized parts, and subgrain size in unrecrystallized regions as forging temperature, speed of quench after forging, and subsequent annealing treatments are varied.

\begin{tabular}{|c|c|c|c|}
\hline $\begin{array}{l}\text { Treatment } \\
\text { conditions }^{\mathrm{a}}\end{array}$ & $\begin{array}{c}\text { Recrystallization } \\
(\%)\end{array}$ & $\begin{array}{l}\text { Grain size } \\
(\mu \mathrm{m}) \text { in } \\
\text { recrystallized } \\
\text { regions }\end{array}$ & $\begin{array}{l}\text { Subgrain size } \\
(\mu \mathrm{m}) \text { in } \\
\text { unrecrystallized } \\
\text { regions }\end{array}$ \\
\hline $400 \mathrm{Q}$ & $\ldots$ & $\cdots$ & $\ldots$ \\
\hline $500 \mathrm{Q}$ & $\ldots$ & $\ldots$ & $\ldots$ \\
\hline $600 \mathrm{SQ}$ & $\cdots$ & $\cdots$ & $\cdots$ \\
\hline $700 \mathrm{Q}$ & $\approx 0$ & $\ldots$ & $1-2$ \\
\hline $800 \mathrm{Q}$ & 15 & 5 & $1-2$ \\
\hline $800 \mathrm{Q}+\mathrm{A}$ & 90 & 20 & \\
\hline $900 \mathrm{Q}$ & 35 & $7-10$ & 2 \\
\hline $900 \mathrm{SQ}$ & 70 & $10-15$ & \\
\hline $900 \mathrm{SQ}+\mathrm{A}$ & 90 & 15 & \\
\hline $1000 \mathrm{Q}$ & 50 & 15 & $2-5$ \\
\hline
\end{tabular}

${ }^{\text {a }}$ The number indicates the forging temperature $\left({ }^{\circ} \mathrm{C}\right)$; Q or SQ refers to an immediate or a slow (after $5 \mathrm{~s}$ ) quench after forging; A refers to a 10 min anneal at $800{ }^{\circ} \mathrm{C}$.

fine equiaxed grains or subgrains were sometimes found at regions inside initial grains and, more commonly, along the boundaries and triple points of the original grains, Fig. 3(b). The area fraction of new, equiaxed grains produced by recrystallization was estimated to be about $15 \%$, with a grain size of about $5 \mu \mathrm{m}$.

Forging at $900{ }^{\circ} \mathrm{C}$ and higher temperatures, followed by an immediate quench, leads to gradually larger amounts of recrystallized regions, with the grain size also being larger, as illustrated in Fig. 4(a). In a similar way, the $5 \mathrm{~s}$ hold after forging at $900{ }^{\circ} \mathrm{C}$ before quenching, as well as a $10 \mathrm{~min}$ anneal at $800{ }^{\circ} \mathrm{C}$ at the end of forging, Fig. 4(b), leads to increased amounts of recrystallization with larger grain sizes. The data, summarized in Table I, show the steady increase in recrystallized fraction, larger grain size of the recrystallized region, and increase in subgrain size of the unrecrystallized parts as the treatment temperature or the hold time at high temperature increases. These results emphasize the speed with which recovery and recrystallization processes occur at such temperatures $\left(800-1000{ }^{\circ} \mathrm{C}\right.$ ) after the heavy forging deformation. In fact, it is clear that $10 \mathrm{~min}$ at $800{ }^{\circ} \mathrm{C}$ are essentially sufficient to fully recrystallize these samples and, more importantly from the point of view of distinguishing deformation and recovered/recrystallized structures, even a time as short as $5 \mathrm{~s}$ at $900{ }^{\circ} \mathrm{C}$ immediately after forging is sufficient to significantly modify the structures. It is also clear that at temperatures of $800-1000{ }^{\circ} \mathrm{C}$, significant recovery/recrystallization takes place either during the short period after forging before quenching $(<1 \mathrm{~s})$ or takes place dynamically during deformation itself, as suggested by the stress-strain curves of Fig. 1 . 
(a)

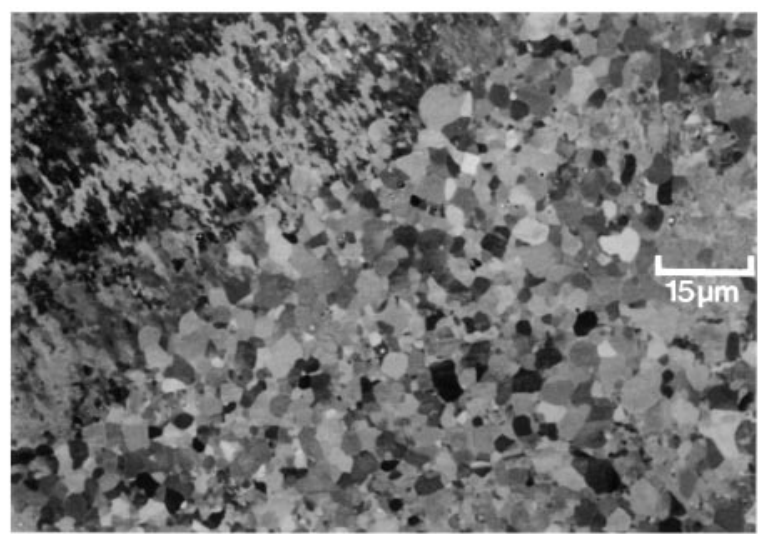

(b)

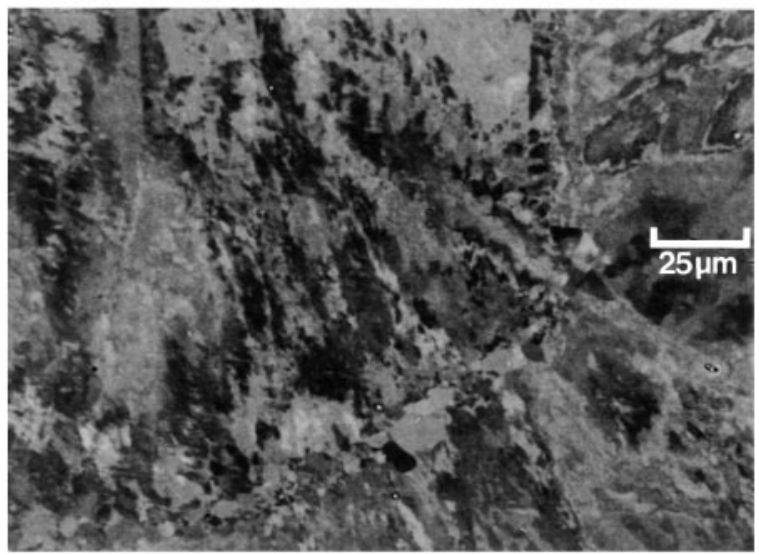

FIG. 3. Backscattered electron images showing deformation cell, subgrain, and newly formed grain structures in a sample forged at $800{ }^{\circ} \mathrm{C}$. (a) shows regions inside initial grains where elongated cells and equiaxed grains/subgrains are seen; (b) shows a triple point region of the original grains, showing elongated cells inside the grains and recrystallized grains along the original grain boundaries.

\section{X-ray examinations}

X-ray spectra were obtained on transverse sections of each sample, scanning over the angular range $(2 \theta)$ of about 30 to $90^{\circ}$, and two examples of results obtained are shown in Fig. 5. The samples were always well B2 ordered, as indicated by the strong superlattice reflections $(100,111$, etc.), but no analyses of the state of order were carried out here. The examples of Figs. 5(a) and 5(b) show the samples forged at $800{ }^{\circ} \mathrm{C}$ and quenched, and the same sample after an anneal of $10 \mathrm{~min}$ at $800{ }^{\circ} \mathrm{C}$, respectively. The forged state is characterized by a very strong 111 reflection, a strong 110 reflection, and weaker 211 and weak 200 reflections. When the data are normalized against the textureless powder spectrum and relative peak frequency summed to unity, this state is characterized by plane fractions $110 / 111 / 200 / 211$ of $0.02 / 0.89 / 0.05 / 0.05$ : thus there is a very strong fraction of $\{111\}$ plane families parallel to the transverse section, with only small amounts of other families of planes. The forged and annealed sample of Fig. 5 is characterized by strong 110 and 200 reflections with weak 211 and very (a)

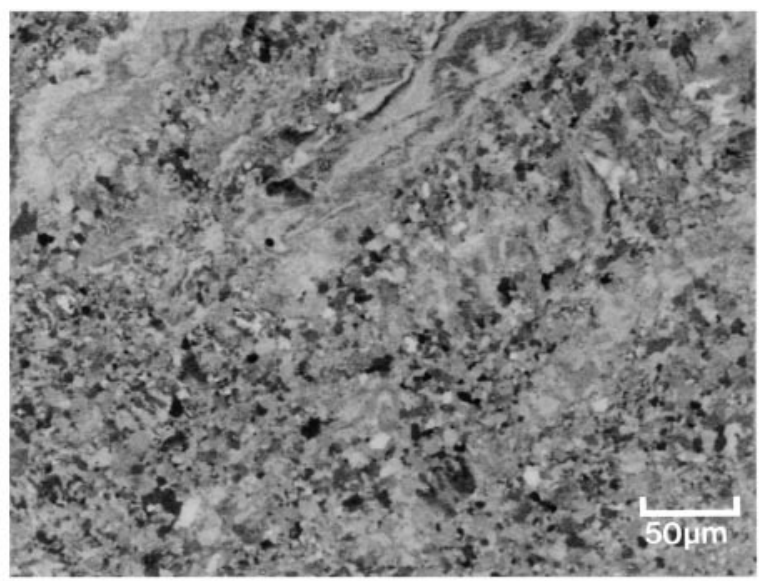

(b)

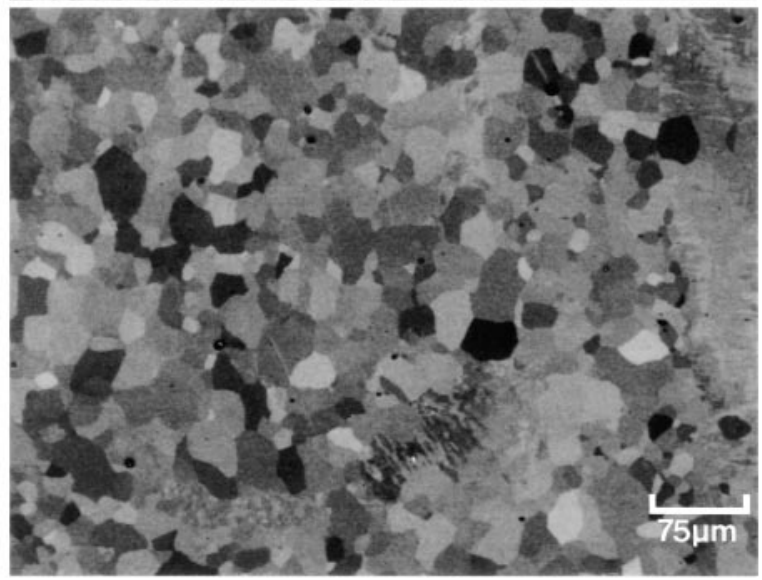

FIG. 4. Backscattered electron images showing microstructures (a) after forging at $900{ }^{\circ} \mathrm{C}$ followed by a quench, where a largely recrystallized region of grain size about $10 \mu \mathrm{m}$ and a region of deformation cells are seen, and (b) after forging at $800{ }^{\circ} \mathrm{C}$, quenching, and annealing for $10 \mathrm{~min}$ at $800{ }^{\circ} \mathrm{C}$, showing a mostly recrystallized structure with grain size of about $20 \mu \mathrm{m}$.

weak 111 reflections: the families of planes parallel to the transverse section are then especially $\{200\}$ planes, with small and equal amounts of the other three types of planes. It should be noted that the differences between the relative intensities of the Bragg reflections in Fig. 5 and the relative frequencies of given families of planes in the samples, as for the $0.02 / 0.89 / 0.05 / 0.05$ example above, are due to variations of the efficiency of x-ray reflection of the planes, as determined by multiplicity, structure factor, and Lorentz-polarization terms. ${ }^{24}$

The relative fractions of each plane $(110,111,200$, and 211) parallel to the transverse section through the sample deduced from such x-ray data are shown in Table II. The initial state, dependent on its casting, forging, and annealing history, shows a fairly weak texture, with $\{110\},\{111\}$, and $\{200\}$ planes having almost the same frequency parallel to the section surface. Forging at low temperatures $\left(400-800{ }^{\circ} \mathrm{C}\right)$ and quenching well (Q samples) leads to a significant increase in the fraction of $\{111\}$ planes, weakening the $\{110\},\{200\}$, and $\{211\}$ 

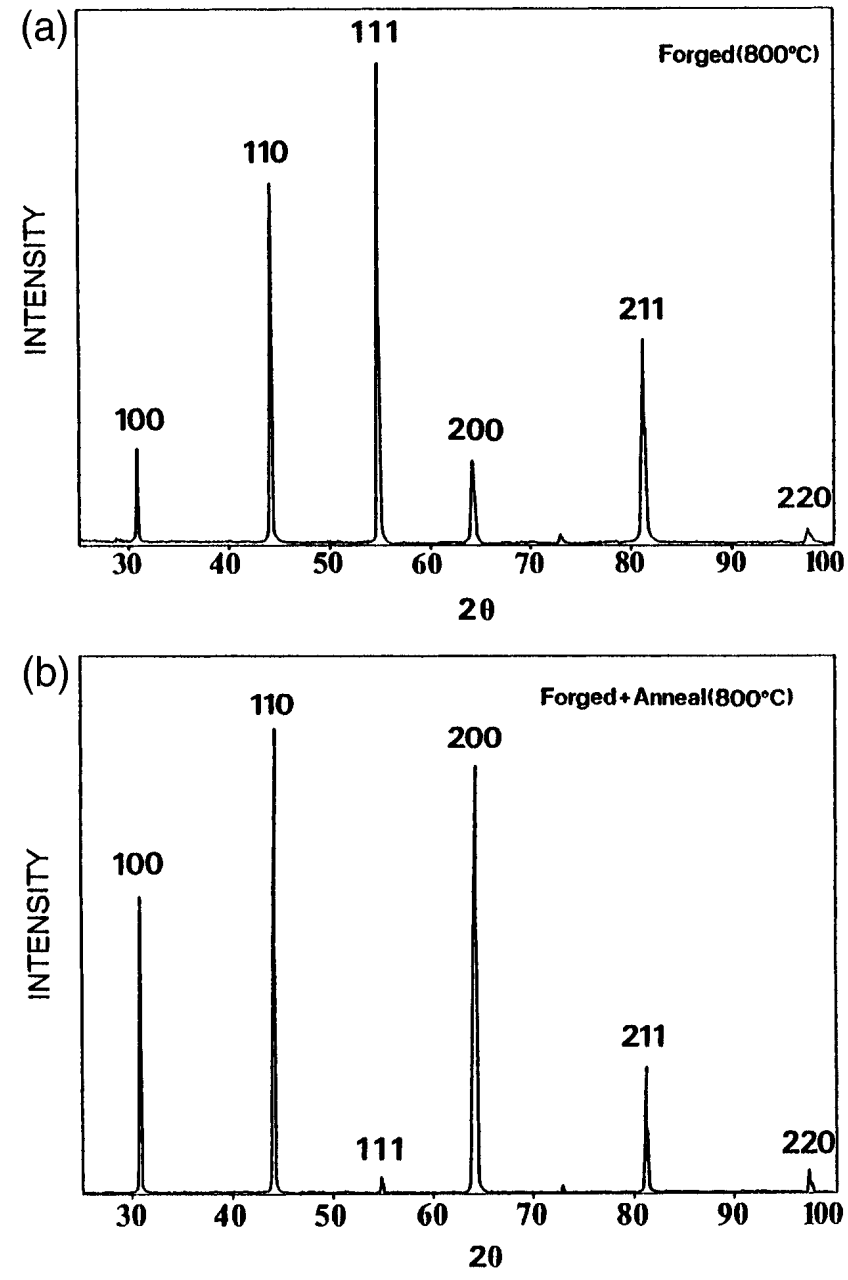

FIG. 5. Illustrations of x-ray spectra obtained on (a) the sample forged at $800{ }^{\circ} \mathrm{C}$ and quenched, and (b) the same sample after a subsequent anneal of $10 \mathrm{~min}$ at $800{ }^{\circ} \mathrm{C}$. planes. Of special interest also is to note the steady increase in the fraction of $\{111\}$ planes and decrease in the fraction of $\{200\}$ planes as the temperature increases from 400 to $800{ }^{\circ} \mathrm{C}$. Recrystallization of the sample forged at $800{ }^{\circ} \mathrm{C}$ by an anneal of $10 \mathrm{~min}$ at $800{ }^{\circ} \mathrm{C}$ $(800 \mathrm{Q}+\mathrm{A})$ leads to a strong $\langle 200\rangle$ texture, significantly weakening the $\langle 111\rangle$ texture. Deforming at $900{ }^{\circ} \mathrm{C}$ (and fast quenching) leads to a similar general texture to that after deformation at $800{ }^{\circ} \mathrm{C}$, except that the $\{111\}$ planes are not so frequent and the $\{200\}$ planes remain present as a significant fraction; such a result can be seen as a mixture of the $800{ }^{\circ} \mathrm{C}$ deformation texture (mostly) with some (slight) addition of the annealing texture. The sample forged at $900{ }^{\circ} \mathrm{C}$ and given a delayed quench (900 SQ) is also seen to have a mixture of the deformation and annealing textures, with a larger proportion of the annealing texture. Further annealing this sample (900 SQ + A) leads to an annealed texture essentially similar to that of the $800 \mathrm{Q}+\mathrm{A}$ sample. Finally, the sample forged at $1000{ }^{\circ} \mathrm{C}$ and quenched (1000 Q) is seen to have texture essentially intermediate between those of the $900 \mathrm{Q}$ and 900 SQ samples, and thus has a mixed deformation and annealing texture.

This analysis allows a clear distinction between the supposedly ideal deformation texture, seen only when deforming at low temperature and quenching efficiently, and the ideal annealing texture, found after well recrystallizing these deformed materials. It is also made clear that deformation experiments carried out at excessively high temperatures, e.g., $1000{ }^{\circ} \mathrm{C}$, or when short anneals are given after forging (including inefficient quenches), will lead to modified deformation textures, where changes toward the annealing texture can be distinguished. Finally, and importantly for a later analysis of the slip systems operating during forging, the deformation texture may be characterized by (relative

TABLE II. Relative proportions of x-ray intensities (normalized against the powder spectrum and the strongest reflection) and fractions of each type of crystal plane in transverse sections through forged cylinders. The major texture component is indicated in bold.

\begin{tabular}{|c|c|c|c|c|c|c|c|c|}
\hline \multirow[b]{2}{*}{ Material state ${ }^{\mathrm{a}}$} & \multicolumn{4}{|c|}{$\mathrm{X}$-ray peak intensity } & \multicolumn{4}{|c|}{ Fraction of planes of given type } \\
\hline & 110 & 111 & 200 & 211 & $\{110\}$ & $\{111\}$ & $\{200\}$ & $\{211\}$ \\
\hline Initial & 1 & 0.63 & 0.7 & 0.22 & 0.39 & 0.25 & 0.27 & 0.09 \\
\hline $400 \mathrm{Q}$ & 0.01 & 1 & 0.13 & 0.09 & 0.01 & 0.82 & 0.11 & 0.07 \\
\hline $500 \mathrm{Q}$ & 0.01 & 1 & 0.1 & 0.08 & 0.01 & 0.85 & 0.09 & 0.05 \\
\hline $600 \mathrm{SQ}$ & 0.01 & 1 & 0.1 & 0.05 & 0.01 & 0.86 & 0.08 & 0.04 \\
\hline $700 \mathrm{Q}$ & 0.01 & 1 & 0.07 & 0.05 & 0.01 & 0.87 & 0.07 & 0.04 \\
\hline $800 \mathrm{Q}$ & 0.02 & 1 & 0.05 & 0.05 & 0.02 & 0.89 & 0.05 & 0.05 \\
\hline $800 \mathrm{Q}+\mathrm{A}$ & 0.09 & 0.14 & 1 & 0.12 & 0.07 & 0.1 & 0.74 & 0.09 \\
\hline $900 \mathrm{Q}$ & 0.02 & 1 & 0.38 & 0.08 & 0.01 & 0.7 & 0.23 & 0.06 \\
\hline $900 \mathrm{SQ}$ & 0.13 & 1 & 0.59 & 0.12 & 0.07 & 0.54 & 0.32 & 0.07 \\
\hline $900 \mathrm{SQ}+\mathrm{A}$ & 0.24 & 0.21 & 1 & 0.16 & 0.15 & 0.13 & 0.62 & 0.1 \\
\hline $1000 \mathrm{Q}$ & 0.16 & 1 & 0.25 & 0.27 & 0.09 & 0.6 & 0.15 & 0.16 \\
\hline
\end{tabular}

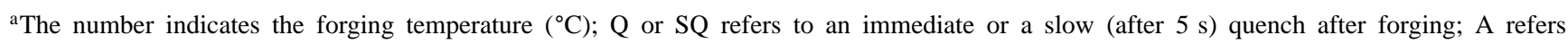
to a 10 min anneal at $800{ }^{\circ} \mathrm{C}$. 
to the starting texture) a major increase in the $\langle 111\rangle$ texture at all forging temperatures, with a corresponding decrease in the strength of $\langle 110\rangle$ and $\langle 200\rangle$ components. The $\langle 211\rangle$ texture is also weakened during deformation, but to a lesser extent. At very high temperatures there is a new increase in the $\langle 200\rangle$ texture component, which can be associated with the onset of recrystallization. Such recrystallization may occur dynamically at the highest temperatures (e.g., $1000{ }^{\circ} \mathrm{C}$ ) and during the short times between deformation and quenching (e.g., the $900 \mathrm{SQ}$ sample). At low deformation temperatures, below $800{ }^{\circ} \mathrm{C}$ and progressively down to $400{ }^{\circ} \mathrm{C}$, there is also a progressive increase in the $\langle 200\rangle$ texture component, from 5 to $11 \%$.

\section{Transmission electron microscopy}

Examinations of dislocation structures in samples forged at relatively low temperatures showed intense dislocation structures, some tendency to the appearance of dislocation cells, with the majority of dislocations being glissile $\langle 111\rangle$ dislocations. There was in fact a gradual evolution of dislocation types from the lowest temperature, $400{ }^{\circ} \mathrm{C}$, to the highest examined, $800-1000{ }^{\circ} \mathrm{C}$, namely as the $\langle 111\rangle$ superdislocations gave way to $\langle 100\rangle$ dislocations. A few examples of dislocations and dislocation structures found at the high temperatures will be presented, and an overview of dislocations over the entire temperature range given in table form. A more detailed analysis of individual dislocation structures will be presented at a later time.

Micrographs illustrating dislocation arrangements in the material forged at $800{ }^{\circ} \mathrm{C}$ and quenched are shown in Figs. 6-8. Figure 6 shows a low magnification image of the unrecrystallized part of this sample showing the loose subgrain structure, of size about $1-2 \mu \mathrm{m}$. The subgrains in this region all have an orientation near $\langle 111\rangle$, which is consistent with the texture deduced by the $\mathrm{x}$-ray examination (Table II). The misorientation across the subgrain boundaries is estimated from Kikuchi line displacements as being less than about $2^{\circ}$.

Figure 7 illustrates some of the typical dislocations and dislocation configurations found within some of the subgrains, for example at A in Fig. 6, and illustrates part of their analysis by tilting to other zone axes and imaging using other $\mathbf{g}$ vectors. It should be emphasized at this point that a very large number of dislocations was analyzed for each material state, typically of the order of 250-300 dislocations: the term analysis implying tilting to at least three major and nonzonal zone axes (for example from the initial [111], to [011], [101], and to either [001] or [110]) to determine line directions, imaging with sufficient $\mathbf{g}$ vectors to distinguish Burgers vectors of type $\langle 100\rangle,\langle 110\rangle$, and $\langle 111\rangle$ (for example imaging with $\overline{1} 01,0 \overline{1} 1, \overline{1} 10,200$, and 020 g vectors),

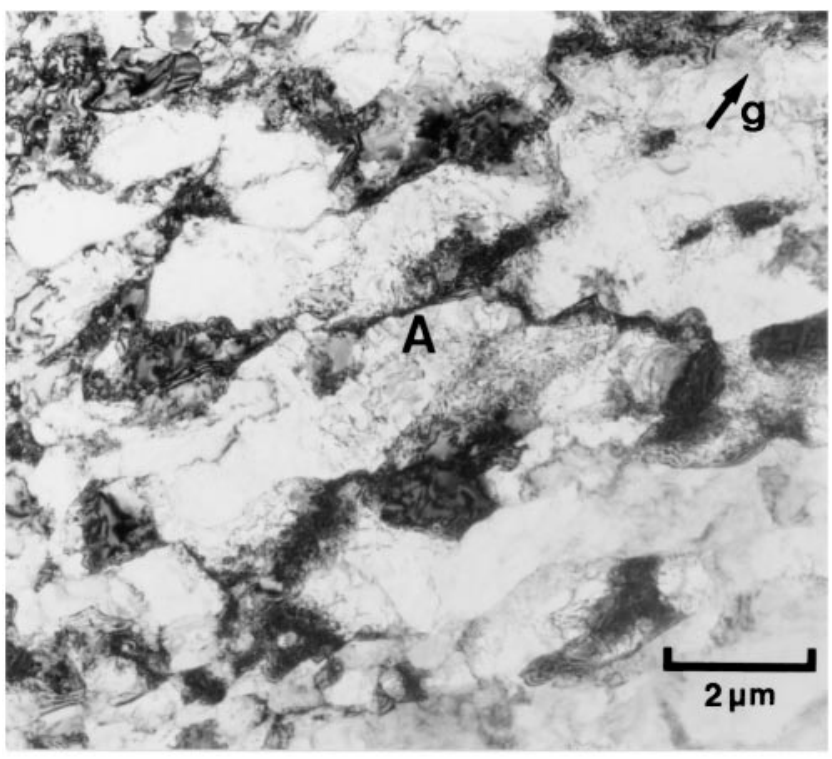

FIG. 6. Electron micrograph showing typical loose subgrain structure in a sample forged at $800{ }^{\circ} \mathrm{C}$ and rapidly quenched. Zone axis, parallel to the compression direction, is [111]. Imaging $\mathbf{g}$ vector (shown) is $\overline{1} 01$.

(a)

(b)

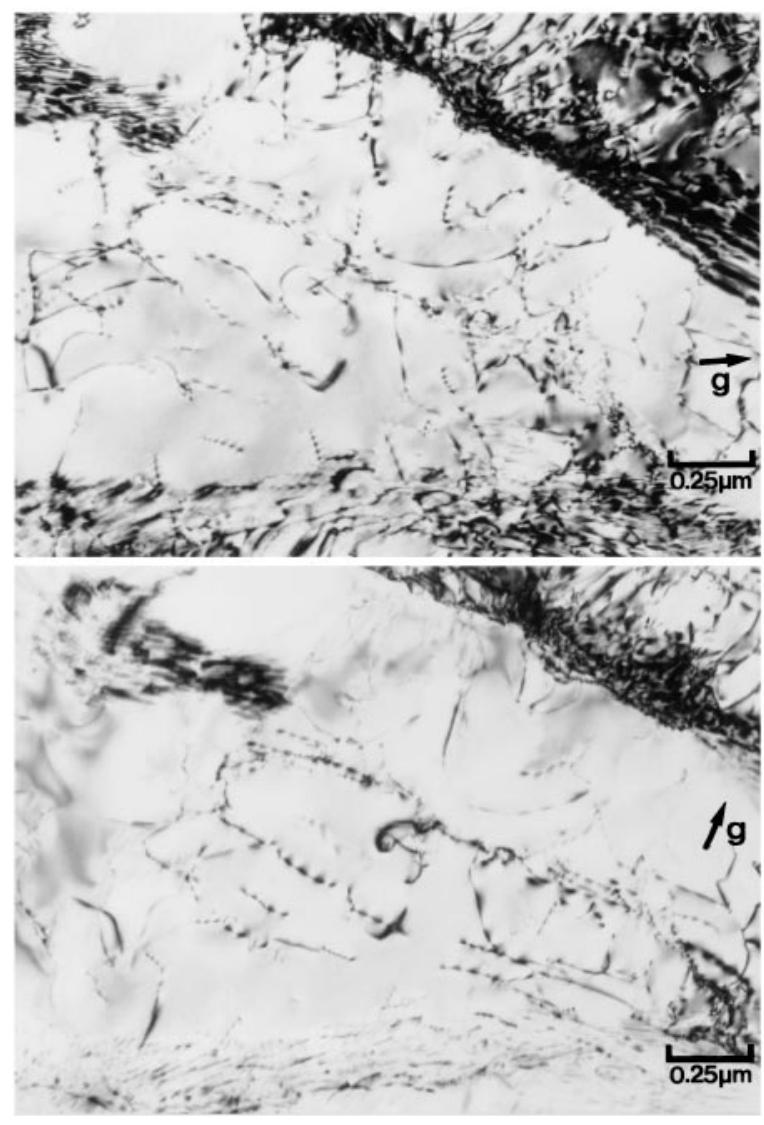

FIG. 7. Electron micrographs showing dislocations inside the subgrain at A in Fig. 6, imaged with (a) zone axis [111], g vector (shown) $\overline{1} 01$, and (b) zone axis [011], g vector (shown) $0 \overline{1} 1$. 
(a)

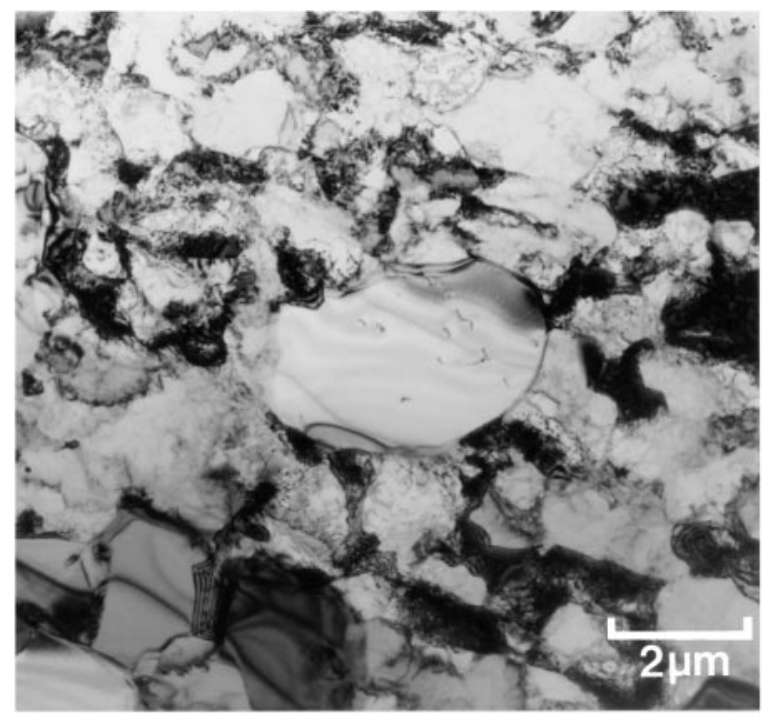

(b)

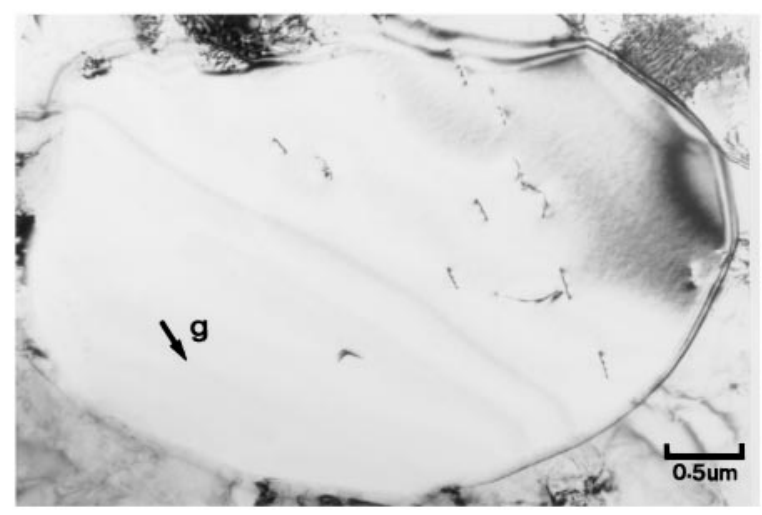

FIG. 8. Electron micrographs showing (a) a recrystallized grain and (b) the small number of dislocations inside the new grain. The zone axis of the recrystallized grain is near [001] in both cases, with an imaging $\mathbf{g}$ vector (shown) 020.

and also several subgrains in a given region of foil and several different foils were examined. The dislocations of Fig. 7, and other regions in the same sample, were almost entirely of Burgers vector $\langle 100\rangle$, and are thus single, perfect dislocations, and only occasionally were APB-dissociated $\langle 111\rangle$ superdislocations and $\langle 110\rangle$ dislocations found.

The dislocations found in such $800{ }^{\circ} \mathrm{C}$ forged samples can be described as follows, with quantitative data given in Table III, for this deformation temperature as well as for the other temperatures examined. The vast majority of the dislocations were of Burgers vector $\langle 100\rangle$, which were present in unequal numbers of all three variants, more [100] than [010] than [001] in Table III. Such dislocations were typically present in $45-90^{\circ}$ edge directions, for example for [100] dislocations in directions such as [110], [130], and [010], and have glide planes corresponding to $\{001\}$ or $\{011\}$. The dislocations found on $\{001\}$ planes have high Schmid factors, while those on $\{011\}$ may have high or low Schmid factors. In addition, a few $\langle 111\rangle$ superdislocations were found, typically in $45-60^{\circ}$ edge directions, and lying on $\{110\}$ type planes with intermediate to high Schmid factors. Some $\langle 110\rangle$ dislocations have also been identified, generally lying on their orthogonal $\{110\}$ plane, with a zero Schmid factor, or occasionally lying on a $\{121\}$ plane, with a high Schmid factor. This quantitative analysis allows the following deductions about the operating slip systems: most deformation is carried by $\langle 100\rangle\{001\}$ (mostly) and $\langle 100\rangle\{011\}$ (slightly) slip systems; the presence of substantially different proportions of dislocations for each variant of $\langle 100\rangle$ Burgers vector implies that their origin was slip and not the decomposition of initial $\langle 111\rangle$ superdislocations, since this would presumably give approximately equal numbers of each type; the small number of $\langle 110\rangle$ dislocations with zero Schmid factors may have been produced by reactions of different $\langle 100\rangle$ dislocations - such reactions were occasionally seen - or perhaps by the decomposition of $\langle 111\rangle$ superdislocations, but this was not observed here. The observation of only a few $\langle 111\rangle$ superdislocations may suggest that only a very small amount of deformation occurs by $\langle 111\rangle$ slip (assuming that most of the dislocations producing deformation are retained in the foil samples, and have not been significantly modified after their creation).

Occasional recrystallized grains were seen during the TEM studies of this $800{ }^{\circ} \mathrm{C}$ forged sample, as illustrated in Fig. 8. Such recrystallized grains were usually found isolated in the unrecrystallized subgrain regions, which retained the same appearance throughout the sample. Such recrystallized grains had sizes of the order of $3-5 \mu \mathrm{m}$ and had orientations of usually $\langle 001\rangle$ and sometimes $\langle 011\rangle$, in general agreement with the $\mathrm{x}$-ray texture data (Table II). Such recrystallized grains usually contained a small number of dislocations, which may be produced either during deformation itself (if recrystallization occurred before the end of the forging process) or during the quenching stage due to thermal stresses generated by the quench. In the example shown in Fig. 8, most of the dislocations were determined to have Burgers vector of type $\langle 110\rangle$, occasionally $\langle 100\rangle$ and $\langle 111\rangle$, with Schmid factors near zero for almost all dislocations. Such a low Schmid factor (determined in relation to the force applied along the cylinder axis) suggests that either it was compatibility stresses between the soft, just-recrystallized grain and the surrounding hard, unrecrystallized subgrains, or quenching stresses that led to the appearance of these dislocations. There were few signs of dislocation reactions between the few dislocations present in these grains, and the origin of the $\langle 110\rangle$ dislocations is not clear. In other such grains with $\langle 100\rangle$ orientations, many of the dislocations found were of $\langle 100\rangle$ Burgers vector, with low Schmid factors, as well as some $\langle 110\rangle$ and a few $\langle 111\rangle$ dislocations. In recrystallized 
TABLE III. Statistical data on the distribution of dislocation types, their habit planes, and the Schmid factors corresponding to these slip planes, for samples deformed by forging and rapid quenching. $\mathrm{m}$ refers to Schmid factor deduced from forging axis, dislocation Burgers vector, and glide plane.

\begin{tabular}{|c|c|c|c|}
\hline $\begin{array}{c}\text { Forging } \\
\text { temperature }\left({ }^{\circ} \mathrm{C}\right)\end{array}$ & $\begin{array}{c}\text { Relative proportion of } \\
100-110-111 \text { dislocations }\end{array}$ & $\begin{array}{c}\text { Relative proportion of } \\
100-010-001 \text { dislocations }\end{array}$ & $\begin{array}{c}\text { Characteristics of }\langle 111\rangle \\
\text { superdislocations }\end{array}$ \\
\hline $400{ }^{\circ} \mathrm{C}$ & $0.12-0.01-0.87$ & $\begin{array}{l}0.8-0.2-0 \\
\text { Typically edge dislocations } \\
\text { On }\{110\} \text { planes } \\
\text { m: low to moderate }\end{array}$ & $\begin{array}{l}\text { Mostly screws } \\
\text { Where analyzed are on } \\
\{110\} \text { planes } \\
\text { m: moderate to high }\end{array}$ \\
\hline $500{ }^{\circ} \mathrm{C}$ & $0.23-0.12-0.65$ & $\begin{array}{l}0.8-0.2-0 \\
\text { Typically edge dislocations } \\
\text { On }\{100\} \text { and }\{110\} \text { planes } \\
\text { m: low to moderate }\end{array}$ & $\begin{array}{l}\text { Mostly screws, more edges } \\
\text { than at } 400{ }^{\circ} \mathrm{C} \text {. } \\
\text { On }\{110\} \text {, occasionally }\{112\} \text { planes } \\
\text { m: high }\end{array}$ \\
\hline $700{ }^{\circ} \mathrm{C}$ & $0.5-0.1-0.4$ & $\begin{array}{l}0.5-0.3-0.2 \\
\text { Typically edge dislocations } \\
\text { On }\{100\} \text { and }\{110\} \text { planes } \\
\mathrm{m}: \text { moderate }\end{array}$ & $\begin{array}{l}\text { Off screw directions } \\
\text { Mostly }\{110\} \text {, few }\{112\} \\
\text { planes } \\
\text { m: high for both systems }\end{array}$ \\
\hline $800{ }^{\circ} \mathrm{C}$ & $0.9-0.05-<0.05$ & $\begin{array}{l}0.45-0.35-0.2 \\
\text { Typically edge dislocations } \\
\text { Mostly }\{100\}, \text { some }\{110\} \\
\text { m: moderate-high for both }\end{array}$ & $\begin{array}{l}\text { Mixed screw-edge } \\
\text { dislocations } \\
\text { Mostly }\{110\} \text {, few }\{112\} \\
\text { m: high for both planes }\end{array}$ \\
\hline $1000{ }^{\circ} \mathrm{C}$ & $0.8-0.1-<0.1$ & $\begin{array}{l}0.45-0.35-0.2 \\
\text { Mostly edge dislocations on } \\
\{100\} \text { with } \mathrm{m} \text { high } \\
\text { Few on }\{110\} \mathrm{m} \text { : moderate }\end{array}$ & $\begin{array}{l}\text { Mixed screw-edge } \\
\text { dislocations } \\
\text { Mostly }\{110\} \text { planes } \\
\text { m: moderate to high }\end{array}$ \\
\hline
\end{tabular}

grains of $\langle 110\rangle$ orientation, there were typically $\langle 100\rangle$ dislocations present which also had very low Schmid factors. In all cases, then, it seems likely that either mechanical compatibility stresses or thermal stresses, both of orientations different from the forging direction, were responsible for producing these dislocations.

In summary of the dislocations found in the $800{ }^{\circ} \mathrm{C}$ forged samples: deformed subgrains had orientations generally near $\langle 111\rangle$ and contained a majority of $\langle 100\rangle$ dislocations present in all three variants, but not in equal numbers; these dislocations were present in edge directions and lay on $\{001\}$ and $\{011\}$ planes; a few $\langle 110\rangle$ dislocations were seen, which may have been formed by reactions between $\langle 100\rangle$ dislocations, and a very small number of $\langle 111\rangle$ superdislocations was found. In the recrystallized grains, which had orientations of $\langle 001\rangle$ or sometimes $\langle 110\rangle$, the dislocations present were typically $\langle 110\rangle$ or $\langle 100\rangle$ dislocations, with very low Schmid factors, suggesting that local compatibility stresses between the recrystallized areas and the unrecrystallized matrix were responsible for such deformation.

Equivalent microstructures observed on the $1000{ }^{\circ} \mathrm{C}$ forged and quenched sample are shown in Fig. 9. Microstructures are essentially similar to those observed after the $800{ }^{\circ} \mathrm{C}$ forging, with the difference of being generally coarser. Figure 9(a) shows the typical subgrain structure of this sample, of size about $2-5 \mu \mathrm{m}$, again with generally $\langle 111\rangle$ orientations and misorientations between subgrains of a few degrees. Figure 9(b) shows individual dislocations, a loose dislocation pileup, and a forming sub-boundary inside one such subgrain. Similar to the analyses of the $800{ }^{\circ} \mathrm{C}$ forged material, the $1000{ }^{\circ} \mathrm{C}$ forged sample has about $80 \%$ of the dislocations with Burgers vectors of type $\langle 100\rangle$ (in the example of Fig. 9(b), about $10 \%$ of these are [100], 50\% are [010], and $40 \%$ are [001]), $5-15 \%$ are $\langle 111\rangle$ superdislocations, and $5-15 \%$ are $\langle 110\rangle$ dislocations. The $\langle 100\rangle$ dislocations are again in edge directions and lie on $\{001\}$ and $\{011\}$ planes with generally high Schmid factors. The pileup seen in Fig. 9(b) is composed of such [010] dislocations, lying in the [100] direction, and on the (001) plane. The few $\langle 111\rangle$ superdislocations lie in $\{011\}$ planes and have generally moderate to high Schmid factors, while the $\langle 110\rangle$ dislocations generally have low Schmid factors. At A is seen the reaction of two $\langle 100\rangle$ dislocations to produce a $\langle 110\rangle$ dislocation. Such reactions are assumed to be the origin of the $\langle 110\rangle$ dislocations seen, rather than their formation by glide in view of their low Schmid factors. Figure 10 shows a more detailed example of dislocations in the $1000{ }^{\circ} \mathrm{C}$ forged material, and illustrates the determination of Burgers vectors by tilting and imaging under different conditions. In the area shown, of initial orientation near $\langle 111\rangle$, there are, again, a majority of $\langle 100\rangle$ dislocations and a very small number of $\langle 110\rangle$ and $\langle 111\rangle$ dislocations. Recrystallized grains in the $1000{ }^{\circ} \mathrm{C}$ forged sample tend to have orientations near $\langle 100\rangle$, consistent with the x-ray texture data of Table II, with again most 
(a)

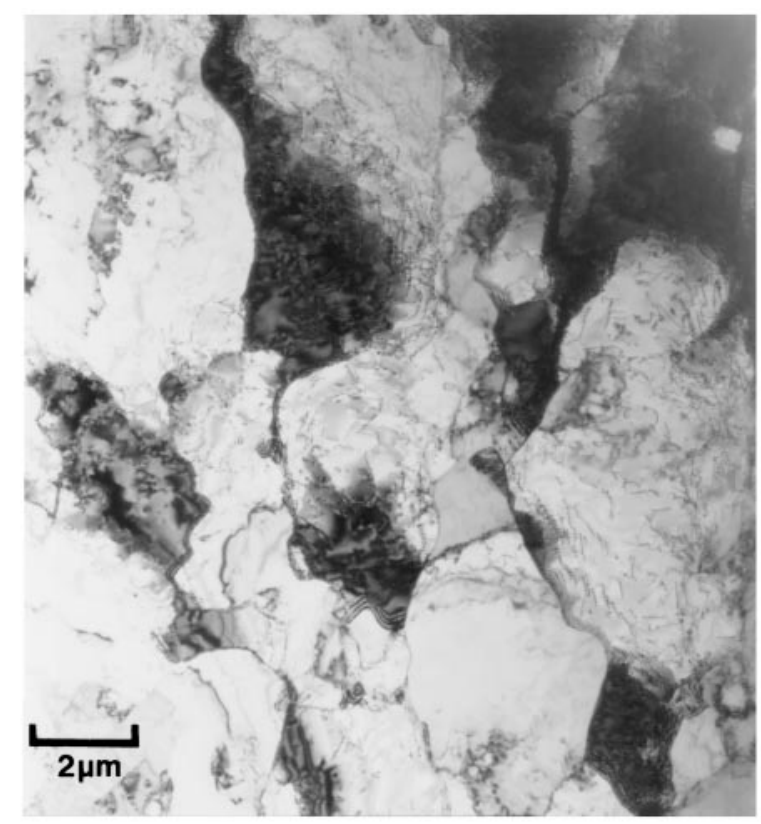

(b)

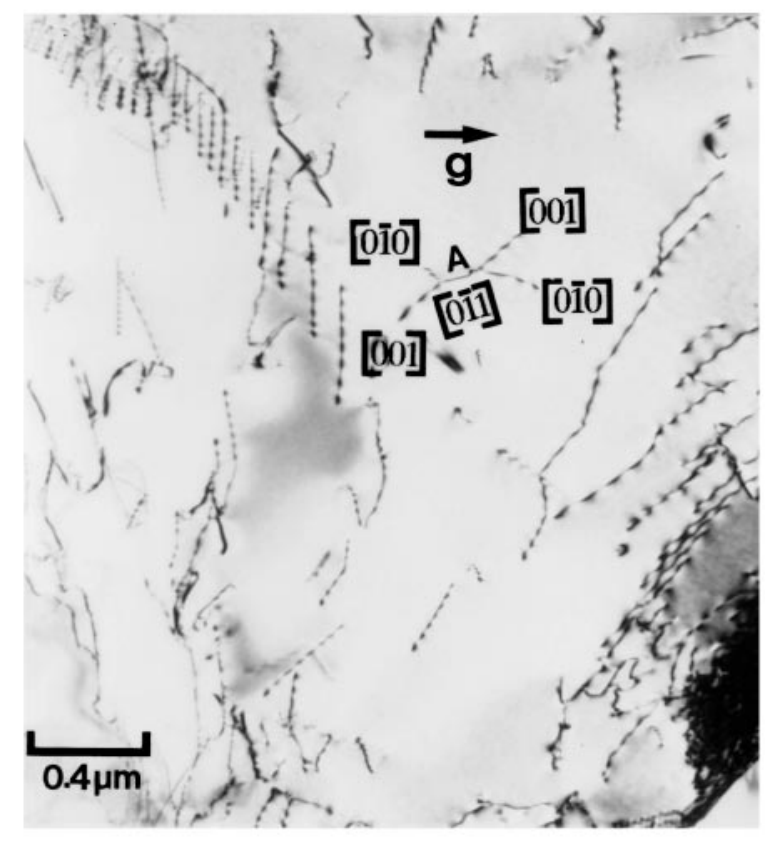

FIG. 9. Electron micrographs showing (a) general subgrain structure and (b) typical dislocations inside a subgrain, of the sample forged at $1000{ }^{\circ} \mathrm{C}$. In (b) the zone axis is near [111], and the imaging $\mathbf{g}$ vector (shown) is $0 \overline{1} 1$.

dislocations being $\langle 100\rangle$ types, with near-zero apparent Schmid factors, and small numbers of $\langle 110\rangle$ and $\langle 111\rangle$ dislocations. Both these dislocations had fairly high apparent Schmid factors, but again it is supposed that local compatibility stresses or quenching stresses are responsible for producing these dislocations.

The summary of dislocation characteristics in Table III shows that the dislocations present after high forging strain and quenching are generally $\langle 111\rangle$ superdislocations at low temperatures with a gradual evolution to mostly $\langle 100\rangle$ dislocations at $800{ }^{\circ} \mathrm{C}$ and higher temperatures. There is not one sharp temperature where the transition in Burgers vector occurs, but rather a steady evolution over the entire temperature range. The $\langle 100\rangle$ dislocations are never observed to be present in equal numbers of each variant ([100], [010], and [001]), which is deduced to imply that they are produced by glide during deformation and not by the decomposition of $\langle 111\rangle$ superdislocations, when more equal numbers of each variant may be expected. These $\langle 100\rangle$ dislocations generally have moderate Schmid factors, consistent with their having been produced by glide. The $\langle 111\rangle$ superdislocations are often in near-screw directions, and lie mostly on $\{110\}$ planes, with high Schmid factors. More, albeit a small fraction, of these superdislocations lie on $\{112\}$ planes over the range of increasing stress. A small fraction of dislocations are identified with $\langle 110\rangle$ Burgers vectors over the entire temperature range. These rarely have high Schmid factors and are believed to be generally formed as junction reactions of $\langle 100\rangle$ dislocations (observed here) or possibly by decomposition of $\langle 111\rangle$ superdislocations (not observed here).

\section{DISCUSSION}

The present work sets out to determine the slip systems operating at high temperatures under high-speed, forging conditions in an FeAl based alloy, to further examine the extent to which post-mortem TEM and x-ray studies lead to a coherent description of deformation, and finally to determine the sensitivity of both deformation structures and textures to the deformation temperature and to subsequent heat treatments on the deformed materials.

Texture measurements are summarized in Table II, using for convenience the relative peak intensities in the small solid angle region parallel to the compression axis. The initial material is seen to be characterized by a very weak texture, with rather similar peak intensities for the four Bragg reflections considered. Deformation is seen to produce a major increase in the proportion of $\{111\}$ planes, with a corresponding decrease in the proportion of $\{110\}$ and $\{200\}$ planes, while the $\{211\}$ planes are reduced only slightly: the $800{ }^{\circ} \mathrm{C}$ forged and quenched sample illustrates such a state. Subsequent recrystallization, for example by the $10 \mathrm{~min}$ at $800{ }^{\circ} \mathrm{C}$ anneal, leads to a major increase in the proportion of $\{200\}$ planes, with a significant fall in the proportion of $\{111\}$ planes, and little change in the proportion of $\{110\}$ and $\{211\}$ planes. All other deformed and annealed states can be understood in terms of the combined contributions of these two texture types, with the transition from the deformed to the recrystallized state evolving steadily at the high temperatures. Using the nomenclature of Table II, 


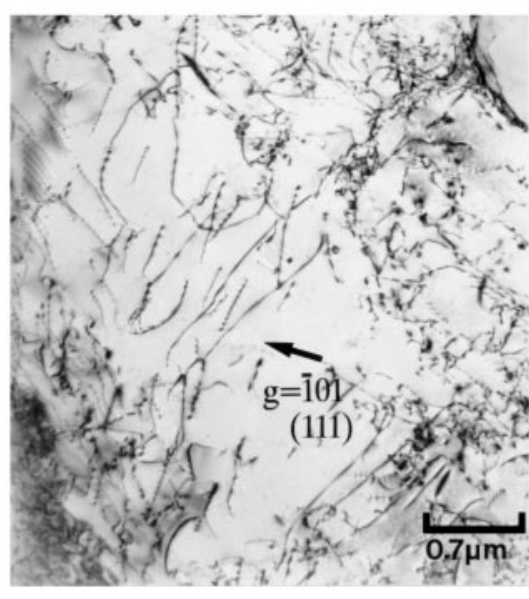

(a)

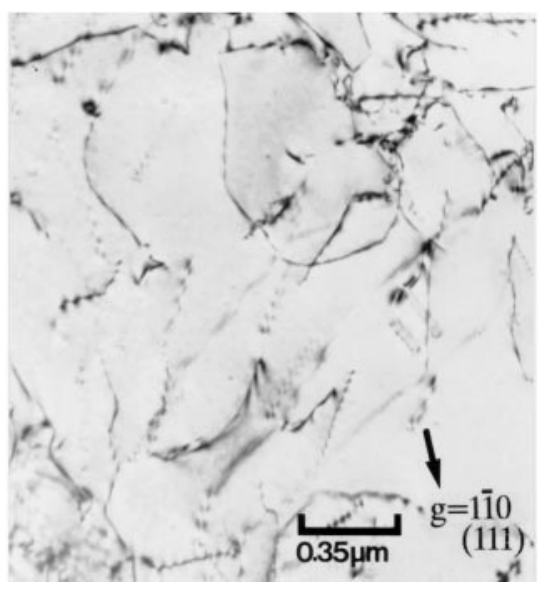

(d)

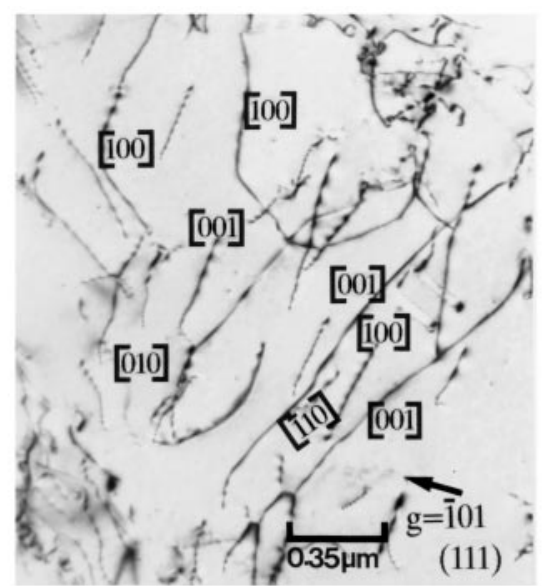

(b)

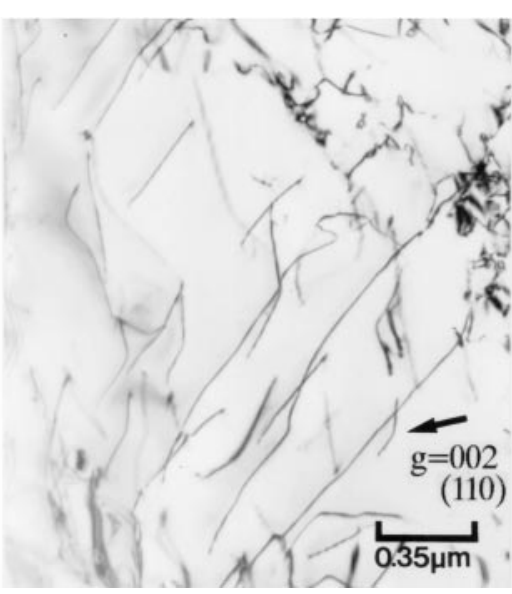

(e)

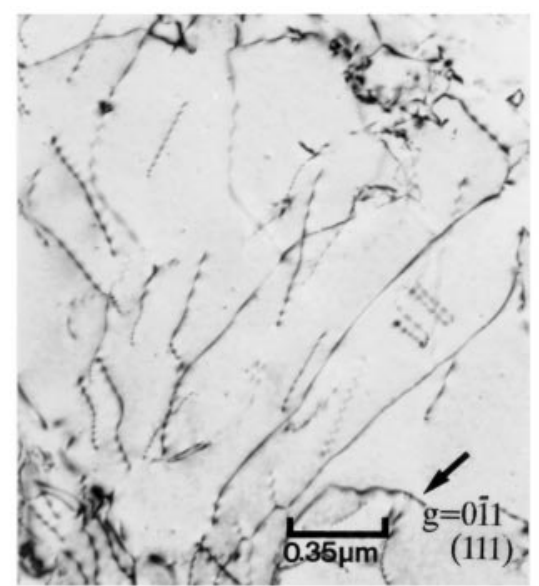

(c)

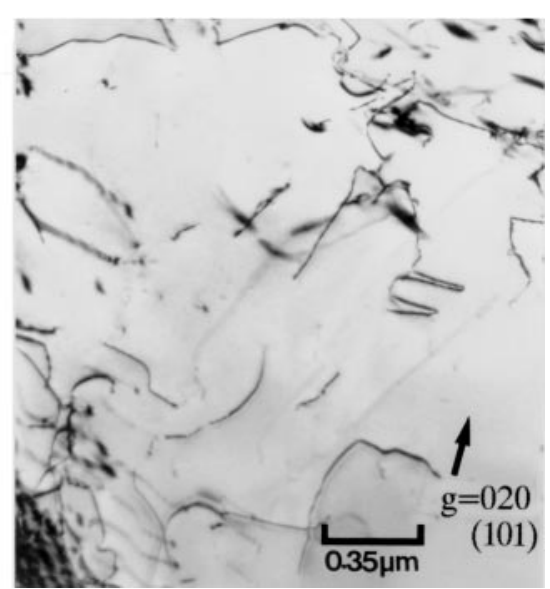

(f)

FIG. 10. Electron micrographs in material forged at $1000{ }^{\circ} \mathrm{C}$ showing the general subgrain structure in (a) and detailed dislocation analysis in (b)-(f). Zone axes and imaging g vectors are shown on micrographs (b)-(f). Burgers vectors of some typical dislocations are identified.

namely defining the forging temperature $(800,900$, or $1000{ }^{\circ} \mathrm{C}$ ), the quench as being normal (Q) or slow (SQ), and the subsequent anneal $(+\mathrm{A})$, the transition from deformed state to recrystallized state takes place in the sequence: 800 Q-900 Q-1000 Q-900 SQ-800/900 Q + A. Most important is to note here that recrystallization begins very rapidly at such high temperatures, essentially completely within $10 \mathrm{~min}$ at $800{ }^{\circ} \mathrm{C}$, but also significantly during the slow quench, that is in $5 \mathrm{~s}$ after forging at $900{ }^{\circ} \mathrm{C}$, and also that even the fast quench from 900 or $1000{ }^{\circ} \mathrm{C}$ is not sufficient to completely avoid recovery and recrystallization. In fact, even at $800{ }^{\circ} \mathrm{C}$, there are signs of the beginning of recrystallization, which appears to be of dynamic nature, thus taking place during deformation itself, but it is believed that the majority of the material remains in the true deformation state corresponding to this temperature. It can also be noted that the analysis here, based on the gradual evolution of texture data (Table II), is completely compatible with data on the extent of recrystallization measured from the microstructural examinations (Table I). These texture data are also compatible with the stress variations observed during the forging process, illustrated in Fig. 1.

At temperatures below $600{ }^{\circ} \mathrm{C}$ there is little recovery and the material shows continuous work hardening during forging; at temperatures of $600-700{ }^{\circ} \mathrm{C}$ there is considerable dynamic recovery and the material shows saturation of work hardening at high strains; at $800{ }^{\circ} \mathrm{C}$ and above there is the onset of dynamic recrystallization and the stress falls at high strain levels as this occurs. The texture data of Table II also give important indications of likely dislocation slip systems during forging; this argument is based on the simulated textures of Kad et al. ${ }^{19}$ who showed that slip on $\langle 111\rangle\{110\}$ or $\langle 111\rangle\{112\}$ systems would lead to very strong $\langle 111\rangle$ fiber textures on extrusion or forging, with a weak $\langle 100\rangle$ fiber texture contribution. Slip on $\langle 100\rangle\{011\}$ systems, on the other hand, would give rise to a similarly strong $\langle 111\rangle$ fiber texture, but there would be no $\langle 100\rangle$ fiber contribution. Thus at the low forging temperatures (see Table II), there 
is a strong $\langle 111\rangle$ fiber texture with a weak but notable $\langle 100\rangle$ contribution, while at progressively high forging temperatures the $\langle 111\rangle$ fiber texture remains but the $\langle 100\rangle$ contribution steadily weakens. The $\langle 100\rangle$ fiber texture contribution is never strong, but nevertheless shows a change by a factor of 2 over the $400-800{ }^{\circ} \mathrm{C}$ range, falling from 0.11 to 0.05 . These changes of texture suggest that deformation has taken place at low temperatures mostly by $\langle 111\rangle$ slip, while at the high temperatures there is a significant contribution of $\langle 100\rangle$ slip.

The TEM study of dislocation structures in the samples deformed at the lower temperatures leads to the conclusion that most of the strain is carried by superdislocations of $\langle 111\rangle$ Burgers vectors which glide on $\{110\}$ planes. At intermediate forging temperatures some of these dislocations are also found on $\{112\}$ planes, but the most important change taking place as the temperature rises is the gradual onset of more and more dislocations with $\langle 100\rangle$ Burgers vectors, which glide on both $\{001\}$ and $\{011\}$ planes. The change from $\langle 111\rangle$ to $\langle 100\rangle$ dislocations is continuous over the $400-800{ }^{\circ} \mathrm{C}$ range, with only a few $\langle 100\rangle$ dislocations observed after forging at $400{ }^{\circ} \mathrm{C}$ and only a few $\langle 111\rangle$ superdislocations found after forging at $800{ }^{\circ} \mathrm{C}$. There is not, however, a critical temperature where the transition of dislocation type occurs. Based on the analyses of the highly curved dislocation segments, and also remembering that deformation takes place at a very high strain rate $(\approx 1 / \mathrm{s})$, there is little indication of extensive climb, and it seems reasonable to deduce that deformation is indeed controlled by glide on the planes identified. There was little dislocation evidence of any significant contribution of other slip systems, with in particular very few dislocations with $\langle 110\rangle$ Burgers vectors found. These $\langle 110\rangle$ dislocations generally have very low Schmid factors, and seem unlikely to have formed by glide. It is more likely that they were produced by reactions between $\langle 100\rangle$ dislocations and less likely that they were the remnants of decomposing $\langle 111\rangle$ superdislocations; occasional examples of combining $\langle 100\rangle$ dislocations to produce $\langle 110\rangle$ junctions were found, but no examples of $\langle 111\rangle$ superdislocation decomposition (for example as $\langle 111\rangle \rightarrow\langle 110\rangle+\langle 001\rangle$ ) were seen here. It is equally unlikely that deformation actually took place by significant $\langle 111\rangle$ slip with the dislocations being destroyed after forging by decomposition. Remnants of such decompositions $(\langle 111\rangle \rightarrow$ $\langle 110\rangle+\langle 001\rangle \rightarrow\langle 100\rangle+\langle 010\rangle+\langle 001\rangle)$ were not observed, and also this decomposition would presumably leave approximately equal numbers of each variant of $\langle 100\rangle$ dislocation- not observed.

TEM studies and texture analyses are thus seen to be mutually consistent in confirming that $\langle 111\rangle$ slip dominates flow (at the high strain rate and to the high strain levels) at low temperatures, near $400-500{ }^{\circ} \mathrm{C}$, while $\langle 100\rangle$ slip on $\{011\}$ and also on $\{001\}$ planes dominates flow at high temperatures, near $800{ }^{\circ} \mathrm{C}$.

The use of texture analyses for determining slip systems operating during deformation suffers from two limitations in the present study: the texture analysis is poorly sensitive to the slip system operating, and very high strain levels are required for significant texture changes. It has been seen in the present analysis that the major texture component remains $\langle 111\rangle$, independent of which slip system controls flow, and it is the detailed examination of the 5 to $11 \%$ contribution of the $\langle 100\rangle$ texture component that must be used to deduce the dominating slip system. The present study has examined textures after $25-45 \%$ strain. Somewhat smaller strain levels could undoubtedly be used and notable changes in texture analyzed, but it is clearly impossible to examine the early stages of plastic flow, e.g., $0.2 \%$ plastic strain, where flow stress analyses are normally made.

The present study provides an interesting comparison of flow stress variations with temperature as the strain rate is increased by almost four orders of magnitude. In the present case the temperature of the flow stress peak is raised about $300{ }^{\circ} \mathrm{C}$ as the strain rate increases from near $10^{-4} / \mathrm{s}$ to about $1 / \mathrm{s}$, while the stress level at the peak is hardly changed; see Fig. 2. A major increase in the stress peak temperature has been proposed $^{7}$ and observed experimentally on several occasions for $\mathrm{FeAl}$ alloys of $40-50 \% \mathrm{Al}^{4,25,26}$ as well as for a $\mathrm{Fe}_{3} \mathrm{Al}$ alloy. ${ }^{27}$ For the $\mathrm{FeAl}$ alloys, observations have typically shown about $100-200{ }^{\circ} \mathrm{C}$ increases in peak temperature and 50-100 MPa increases in peak stress with strain rate increases of 2-3 orders of magnitude. The present increase in peak temperature is consistent with the prior literature data, although the reason why no noticeable change of peak stress is found is not clear. An important difference between the present and prior data is that both the low temperature range, of rising stress with temperature, and the high temperature range, of falling stress with temperature, are displaced to higher temperatures, while previous studies have tended to show little effect of strain rate on the rising stress portion of the data. The available data are so limited, however, depending apparently on the $\mathrm{Al}$ content as well as the actual strain rate values considered, with the strain rate change from $10^{-6} / \mathrm{s}$ to $10^{-3} / \mathrm{s}$ not necessarily having the same effect as the $10^{-3} / \mathrm{s}$ to $10^{0} / \mathrm{s}$ change, that it is not possible to draw further conclusions at the present time.

It is difficult at the present time to deduce here the dislocation mechanisms responsible for the flow stress variations (at $0.2 \%$ strain) on the basis of the texture and dislocation studies carried out at $25-45 \%$ strain. However, two scenarios can be considered to explain the stress rise and fall with increasing temperature. First, it may be proposed that $\langle 111\rangle$ superdislocations initially 
control deformation and determine the $0.2 \%$ flow stress at all temperatures (as suggested by Yoshimi et al. ${ }^{9}$ and $\mathrm{Kad}$ and Horton, ${ }^{13}$ for example), and there is a gradual increase in the contribution of $\langle 100\rangle$ dislocations at higher temperatures and strain levels. At temperatures of $800{ }^{\circ} \mathrm{C}$ and below, it is such $\langle 111\rangle$ superdislocations that control yielding, while at $900{ }^{\circ} \mathrm{C}$ the $\langle 100\rangle$ dislocations take over to dominate flow rather suddenly just after yield, giving rise to the yield plateau similar to that found by Yoshimi et al. ${ }^{9}$ At even higher temperatures the $\langle 100\rangle$ dislocations presumably take over very rapidly, before major yielding, even though $\langle 111\rangle$ superdislocations may have been the first to operate for some microstrain, and thus it is actually $\langle 100\rangle$ dislocations that now control the yield stress. In this scenario, the $\langle 111\rangle$ to $\langle 100\rangle$ transition of Burgers vector occurs gradually as both strain and temperature are increased, but the transition is not related to and does not cause the stress rise. It is the cause of the stress fall since $\langle 100\rangle$ dislocations now dominate flow and become progressively easier to move at the very high temperatures. The cause of the stress rise, when $\langle 111\rangle$ superdislocations control deformation, is not determined in the present study, but may perhaps be correlated with the larger number of these dislocations observed to lie on $\{112\}$ planes as the temperature rises.

In the second scenario, there is considered to be a steady mixture of $\langle 111\rangle$ superdislocations and $\langle 100\rangle$ dislocations for all strain levels (the ratio of each in the mixture may change somewhat with strain but not dramatically), and the fraction of $\langle 100\rangle$ dislocations is determined essentially by the temperature. It is now the appearance of $\langle 100\rangle$ dislocations that leads to the formation of obstacles to the movement of the $\langle 111\rangle$ superdislocations, and hence is the origin of the stress increase. As more $\langle 100\rangle$ obstacles are formed over the $400-800{ }^{\circ} \mathrm{C}$ range, the flow stress rises, and it is only when glide of these $\langle 100\rangle$ dislocations becomes easy that the flow stress may fall. In this scenario, the origin of the yield plateau observed at $900{ }^{\circ} \mathrm{C}$ is unclear. The first scenario is essentially that proposed by Yoshimi, Kad, and other researchers ${ }^{7,9,13}$ for the stress peak observed under usual laboratory testing conditions. The second scenario is that suggested earlier, ${ }^{4-6,11,20}$ whereby the appearance of $\langle 100\rangle$ dislocation segments, either by reaction or by decomposition of $\langle 111\rangle$ superdislocations, is responsible for the stress increase. From the present experiments it is not possible to distinguish between these two scenarios since we do not have information on the dislocation structures immediately after yield or on the variation of dislocation types during straining.

\section{CONCLUSIONS}

The present study has shown that an analysis of the textures produced during heavy deformation can provide information on the dominant slip systems operating over the imposed strain range. The method is poorly sensitive to distinguishing between many of the slip systems of interest, however, particularly for small strain levels. The method is thus unreliable for examination of dislocation processes at yield, since changes in slip systems may occur during straining.

In the present study, the texture studies and the TEM analyses of dislocation structures are consistent in showing that $\langle 111\rangle$ superdislocations dominate deformation at low temperatures, here $400-500{ }^{\circ} \mathrm{C}$, and $\langle 100\rangle$ dislocations on $\{011\}$ planes dominate deformation at very high temperatures, about $800{ }^{\circ} \mathrm{C}$.

The flow stress at yield rises with test temperature to a peak at about $500{ }^{\circ} \mathrm{C}$ for the present alloy when tested at a strain rate near $10^{-4} / \mathrm{s}$, and to a peak at about $800{ }^{\circ} \mathrm{C}$ when forged at a strain rate of about $1 / \mathrm{s}$. The peak stress level is similar for both strain rates. From the present study, which has analyzed dislocation structures and slip systems only after deforming to $25-45 \%$ strain, it is not possible to deduce the role of the $\langle 111\rangle$ to $\langle 100\rangle$ transition on the yield stress changes, since this transition may occur from the beginning of plastic deformation or may set in at a later strain, after yield.

\section{ACKNOWLEDGMENTS}

One of us (PZ) would like to acknowledge the financial support of the following agencies during the course of this research: the Swiss Federal Commission for an Exchange Student grant, and the Swiss National Science Foundation for a doctoral grant.

\section{REFERENCES}

1. W. Schroer, H. Mecking, and C. Hartig, in Proc. Int. Symp. Intermetallic Compounds - Structure and Mechanical Properties (JIMIS-69), edited by O. Izumi, The Japan Institute of Metals, Sendai (1991), p. 567.

2. W. Schroer, C. Hartig, and H. Mecking, Z. Metall. 84, 294 (1993).

3. D. G. Morris, D. Peguiron, and M. Nazmy, Philos. Mag. A71, 441 (1995).

4. K. Yoshimi, S. Hanada, and M. H. Yoo, Acta Metall. Mater. 43, 4141 (1995)

5. Y. Umakoshi and M. Yamaguchi, Philos. Mag. A41, 573 (1980).

6. I. Baker, H. Xiao, O. Klein, C. Nelson, and J. D. Whittenberger, Acta Metall. Mater. 43, 1723 (1995).

7. E. P. George and I. Baker, Philos. Mag. A77, 737 (1998).

8. I. Baker, Mater. Sci. Eng. A192/193, 1 (1995).

9. K. Yoshimi, S. Hanada, and M. H. Yoo, in High-Temperature Ordered Intermetallic Alloys VII, edited by C. C. Koch, C. T. Liu, N. S. Stoloff, and A. Wanner (Mater. Res. Soc. Symp. Proc. 460, Pittsburgh, PA, 1997), p. 313.

10. D. G. Morris, in Proc. 4th Int. Conf. on High Temperature Intermetallics, edited by C. T. Liu, S. H. Whang, and D. P. Pope, Mater. Sci. Eng. A239-240, 23 (1997).

11. K. Yoshimi and S. Hanada, in Structural Intermetallics, edited by R. Darolia, J. J. Lewandowski, C. T. Liu, P. L. Martin, D. B. Miracle, and M. V. Nathal (TMS, Warrendale, PA, 1993), p. 475. 
12. D. G. Morris, Philos. Mag. A71, 1281 (1995).

13. B. K. Kad and J. A. Horton, in Proc. 4th Int. Conf. on High Temperature Intermetallics, edited by C. T. Liu, S. H. Whang, and D. P. Pope, Mater. Sci. Eng. A239-240, 118 (1997).

14. S. Hanada, S. Watanabe, T. Sato, and O. Izumi, Scripta Metall. 15, 1345 (1981).

15. A. Brinck, C. Engelke, and H. Neuhauser, Mater. Sci. Eng. A234, 418 (1997).

16. G. Molenat, A. Couret, and D. Caillard, Mater. Sci. Eng. A234, 660 (1997).

17. D. Raabe and W. Mao, Philos. Mag. A71, 805 (1995).

18. D. Raabe, Acta Mater. 44, 937 (1996).
19. B. K. Kad, S.E. Schoenfeld, R. J. Asaro, C. G. McKamey, and V. K. Sikka, Acta Mater. 45, 1333 (1997).

20. D. G. Morris and M. A. Morris, Intermetallics 5, 245 (1997).

21. S. A. Scheff, J. J. Stout, and M. A. Crimp, Scripta Metall. et Mater. 32, 975 (1995).

22. D. G. Morris and S. Gunther, Scripta Mater. 35, 1211 (1996).

23. I. M. Anderson, Acta Mater. 45, 3897 (1997).

24. B. D. Cullity, Elements of X-ray Diffraction (Addison-Wesley Pub. Co., Reading, MA, 1956).

25. X. Li and I. Baker, Scripta Mater. 36, 1387 (1997).

26. I. Baker and Y. Yang, Mater. Sci. Eng. A239-240, 109 (1997).

27. D. G. Morris and S. Gunther, Mater. Sci. Eng. A211, 23 (1996). 